\title{
¿Qué exige el principio de responsabilidad en el ámbito de la Administración Pública?
}

\section{What does the Principle of Responsibility in the field of Public Administration require?}

Isabel Lifante Vidal

Universidad de Alicante (España)

ORCID: http://orcid.org/0000-0003-3348-2299

isabel.lifante@ua.es

\section{NOTA BIOGRÁFICA}

Profesora titular de Filosofía del Derecho en la Universidad de Alicante. Sus líneas de investigación se centran en la interpretación del Derecho y en el ejercicio de los poderes públicos, analizando conceptos tales como discrecionalidad, representación, responsabilidad, publicidad, seguridad jurídica, etc.

\section{RESUMEN}

Este trabajo trata de caracterizar en qué consiste el correcto desempeño de la actividad administrativa; dicho de otro modo: cuáles son las exigencias del principio de responsabilidad en el ámbito de la Administración Pública. Para ello, se presenta una caracterización de las peculiaridades de los deberes vinculados al desempeño de responsabilidades. A continuación, se analizan algunos de los «vicios» más comunes de la Administración, conectándolos con los diversos tipos de incumplimientos de las responsabilidades: la corrupción, el formalismo, la desidia y la incompetencia. Dado que las causas de estos incumplimientos son distintas, el trabajo remarca que también deberán serlo las estrategias adecuadas para luchar contra ellos.

\section{PALABRAS CLAVE}

Administración Pública; principio de responsabilidad; vicios de la Administración; corrupción; formalismo; desidia; incompetencia.

\begin{abstract}
This paper tries to characterize what the correct performance of administrative activity consists of. In other words, which are the demands of the principle of responsibility when applied to the field of Public Administration. For these purposes a characterization of the peculiarities of those duties linked to the performance of responsibilities is addressed. Next, some of the most common «vices» of the Administration are analyzed, connecting them with different types of breaches of responsibilities: corruption, formalism, sloth and incompetence. Since the causes of these breaches are different, this paper claims that the appropriate strategies to fight them should be too.
\end{abstract}

\section{KEYWORDS}

Public administration; responsibility principle; corruption; formalism; sloth; incompetence. 


\section{SUMARIO}

1. LAADMINISTRACIÓN PÚBLICA EN UN ESTADO CONSTITUCIONAL 2. ALGUNAS OBSERVACIONES CONCEPTUALES SOBRE LA RESPONSABILIDAD 3. ¿QUÉ TIPO DE DEBERES IMPLICA UNA RESPONSABILIDAD? 4. LA EVALUACIÓN DEL DESEMPEÑO DE LAS RESPONSABILIDADES PÚBLICAS 5. UN CATÁLOGO DE «VICIOS» DE LA ADMINISTRACIÓN PÚBLICA: CORRUPCIÓN, FORMALISMO, DESIDIA E INCOMPETENCIA 6. ALGUNAS IDEAS -MUY PRELIMINARES- PARA LA MEJORA DEL DESEMPEÑO PÚBLICO. REFERENCIAS BIBLIOGRÁFICAS.

\section{LA ADMINISTRACIÓN PÚBLICA EN UN ESTADO CONSTITUCIONAL ${ }^{1}$}

Un Estado constitucional se caracteriza no sólo por rasgos formales (la existencia de una constitución rígida y normativa), sino también por la asunción de los fines y valores del constitucionalismo político, y que se conectan con la limitación del poder político y la garantía de los derechos ${ }^{2}$. Esos rasgos formales del constitucionalismo, la rigidez y la normatividad constitucionales, sólo pueden ser entendidos instrumentalmente, es decir, como garantías de aquello que dota de valor al Estado constitucional y que serían precisamente los derechos del constitucionalismo. Derechos que -siguiendo a Aguiló Regla (2019)- pueden verse como dirigidos a evitar los distintos males que toda dominación política puede potencialmente llegar a producir: la arbitrariedad (los derechos vinculados al debido proceso), el autoritarismo (los derechos de libertad), el despotismo (los derechos de participación política) y la exclusión social (los derechos sociales y de igualdad real).

Un importante rasgo a destacar en los Estados constitucionales será entonces la importancia efectiva otorgada a los «principios» como ingredientes necesarios, además del de las «reglas», para comprender la estructura y el funcionamiento del sistema jurídico, para su interpretación y aplicación ${ }^{3}$. Debe tenerse en cuenta que ambos tipos de normas (principios y reglas) no se diferencian sólo desde la perspectiva de su estructura lógica, sino también a partir del distinto papel que juegan en el razonamiento práctico. Los principios se conectarían con una función justificativa del Derecho o de algunas de sus ramas. Uno de los grandes principios en un Estado constitucional es el principio de legalidad: el sometimiento del Estado a su propio Derecho, a través de la regulación y el control de todos los poderes y actuaciones del Estado por medio de leyes democráticamente creadas. El artículo 9.3 de nuestra Constitución lo recoge, precisando también algunas de las exigencias que del mismo se derivan, como los principios de responsabilidad e interdicción de la arbitrariedad de los poderes públicos. Por supuesto, estas exigencias se proyectan sobre todos los poderes del Estado; por lo que aquí nos interesa, también al Poder Ejecutivo y en particular a la Administración Pública. Respecto a esta última, el artículo 103.1 de la Constitución establece que la misma ha de servir con objetividad los intereses generales y actuar de acuerdo con los principios de eficacia, jerarquía, descentralización, desconcentración y coordinación, con sometimiento pleno a la ley y al Derecho; mientras que el artículo 106.1 establece el control por parte de los Tribunales tanto de la potestad reglamentaria, como de la legalidad de la actuación administrativa, y de su sometimiento a los fines que la justifican.

La teoría general del Derecho se ha ocupado de analizar y discutir profusamente las exigencias que impone el ideal valorativo del Estado de Derecho (el sometimiento de los poderes del Estado al Derecho) desde una perspectiva fundamentalmente centrada en la actividad jurisdiccional y también, aunque en menor medida, en la actividad legislativa. Sin embargo, creo que se han desatendido las peculiaridades que el sometimiento al Derecho exige en el desempeño de otras actividades de los poderes públicos, en particular creo que se ha quedado fuera del foco de atención de nuestros análisis gran parte del ámbito de actuación del Poder Ejecutivo y, especialmente, de la Administración pública. Podría alegarse que no encontramos aquí peculiaridades (respecto a la actividad jurisdiccional y legislativa) dignas de análisis desde el punto de

Para la realización de este artículo he contado con el apoyo del proyecto de investigación "Una teoría postpositivista del Derecho" (DER2017-86443-P), financiado por el Ministerio de Economía y Competitividad español. Este trabajo toma como punto de partida la ponencia "Anomia y función pública" que presenté al I Congreso de filosofía del Derecho para el mundo latino (i-Latina), celebrado en Alicante en 2016, aunque muchas de las tesis que allí sostuve son aquí matizadas o desarrolladas con mayor detalle. Quisiera agradecer las observaciones que Manuel Atienza, Josep Aguiló Regla y Victoria Roca han realizado a un borrador de este trabajo y que, sin duda, han contribuido a mejorarlo.

2 En este mismo sentido, ya la Declaración francesa de los derechos del hombre y del ciudadano, de 1789, decía en su art. 16: «Toda sociedad en la cual no esté establecida la garantía de los derechos, ni determinada la separación de los poderes, carece de Constitución».

3 Sobre la caracterización de la distinción entre reglas y principios que aquí sigo, puede verse ATIENZA y RUIZ MANERO (1996) 
vista de las exigencias normativas del Estado de Derecho. En este sentido, en ocasiones se señala que una parte importante de la actividad que desempeña la Administración consiste en la mera aplicación de normas preexistentes a casos concretos (pensemos en la concesión de una licencia de obras a un particular o en la imposición de sanciones administrativas...) y que dichas actividades podrían por tanto ser equiparadas a la actividad jurisdiccional; y otra parte de la actividad desarrollada desde el Poder Ejecutivo coincidiría con la actividad legislativa (creación de normas generales, aunque de menor jerarquía que la ley). Pero, aunque ello sea cierto, no deja de serlo también que encontramos una gran parte de actividad de la Administración que no presenta naturaleza ni jurisdiccional (mera aplicación subsuntiva de normas), ni legislativa (creación de normas generales); me refiero a la adopción de medidas para el desarrollo de las funciones atribuidas a la Administración, consistentes en perseguir activamente ciertos fines predeterminados por la ley; actividad que en muchas ocasiones presupone el ejercicio de poderes discrecionales. $Y$ es a este tipo de actividad, que -como veremos- se asocia con el desempeño de «responsabilidades» vinculadas al desempeño de ciertos roles o estatus, a la que me quiero referir en este trabajo.

De nuevo, los escasos análisis que podemos encontrar en la teoría del Derecho sobre la actividad discrecional de la Administración se suelen centrar en el papel que desempeña el juez, como garante de la legalidad de la actividad discrecional de la administración. Pero, en mi opinión, esta perspectiva centrada en el control de la actividad administrativa ha dado lugar a una comprensión distorsionada del fenómeno de la discrecionalidad ${ }^{4}$, que es presentada como la facultad de elegir libremente entre dos o más cursos de acción, cada uno de los cuales es concebido como permisible por el Derecho o, lo que es lo mismo, como indiferentes jurídicamente ${ }^{5}$. La actividad jurisdiccional de control exige una respuesta binaria, es decir, ante la admisión de un recurso contencioso-administrativo sólo caben dos opciones: o se desestima por considerar la disposición, el acto o la actuación recurrida conforme a Derecho, o se estima por considerarlo contrario a Derecho ${ }^{6}$. El control jurisdiccional se centra pues en excluir del ordenamiento los resultados inadmisibles de un previo desempeño de discrecionalidad; desde esta perspectiva todos los resultados que no puedan ser excluidos del ordenamiento son vistos como aceptables jurídicamente. Pero eso no implica que, desde la perspectiva de la autoridad administrativa que ha de desempeñar la discrecionalidad, ésta pueda verse como un permiso para optar entre indiferentes jurídicos. Es posible -y frecuente- que en el ejercicio de un poder discrecional existan varias actuaciones que un juez tendría que validar en una tarea de control ex post, pero eso no podrá determinarse hasta después de haber evaluado, a la luz de las circunstancias del caso, su adecuación para la consecución de los fines y objetivos que el sujeto debe perseguir en términos no sólo de eficacia sino también de protección de los valores por los que ha de velar. Y es en dicha actividad de evaluación y comparación de las distintas actuaciones disponibles para elegir una de ellas en lo que en mi opinión consiste el desempeño de la actividad discrecional.

Este trabajo pretende poner el foco de atención en responder a la cuestión de en qué consiste el correcto desempeño de la actividad administrativa; dicho de otro modo, en cuáles son las exigencias del principio de responsabilidad en el ámbito de la Administración Pública de un Estado constitucional. Pero, antes de ello, llevaré a cabo algunas observaciones conceptuales sobre la responsabilidad en general.

\section{ALGUNAS OBSERVACIONES CONCEPTUALES SOBRE LA RESPONSABILIDAD}

La atribución de responsabilidad ocupa un lugar fundamental en el seno de cualquier sistema normativo. Estas atribuciones resultan indispensables, entre otras cosas, para adscribir deberes, para llevar a cabo va-

4 En un sentido similar se pronuncia PONCE SOLÉ (2016: 223-224).

5 Definiciones o aproximaciones de este tipo pueden encontrarse, por ejemplo, en BARAK (1989: 7) o BELL (1992: 92). También en la doctrina administrativista española; así, por ejemplo, en las distintas ediciones del Curso de Derecho Administrativo de EDUARDO GARCÍA DE ENTERRÍA y TOMÁS-RAMÓN FERNÁNDEZ (cfr., por todos, GARCÍA DE ENTERRÍA y FERNÁNDEZ, 1995: 447) y también en SÁINZ MORENO (1976: 304). En un trabajo anterior (LIFANTE VIDAL, 2002) critiqué esta aproximación. En mi opinión, la discrecionalidad implica la responsabilidad de determinar las medidas que, a la luz de las circunstancias de cada caso concreto, optimice los fines o valores a perseguir, lo que implica llevar a cabo evaluaciones y juicios de adecuación medio a fin. Evaluaciones que pueden -y en un Estado de Derecho deben- estar sometidas a control jurídico. Disiento por tanto de la caracterización extendida de que el ejercicio de los poderes discrecionales (o «no reglados») no estarían regulados jurídicamente; en mi opinión lo están, aunque a través de un tipo peculiar de normas jurídicas: las normas de fin.

6 Conviene señalar que el artículo 70.2 de la Ley de Jurisdicción Contenciosa de 1998 señala en este punto expresamente como un tipo de «infracción del ordenamiento jurídico», la desviación de poder, entendiendo por tal (según la propia disposición) «el ejercicio de potestades administrativas para fines distintos de los fijados por el ordenamiento jurídico». 
loraciones de la conducta y para justificar la imposición de sanciones u otras consecuencias gravosas, tales como el deber de reparar o indemnizar ciertos daños. De modo que el de responsabilidad es, sin duda, uno de los conceptos centrales en cualquier contexto normativo y también, por supuesto, en el Derecho. Pero se trata de un término que es usado en el lenguaje ordinario, y en los propios contextos normativos, en sentidos muy distintos (aunque -y eso es importante recalcarlo- conectados entre sí de diversas maneras) ${ }^{7}$.

Si echamos una ojeada a las discusiones sobre la responsabilidad en el ámbito de la filosofía práctica general, nos encontramos con que es considerada uno de los pilares o presupuestos básicos desde una perspectiva deontológica. Así, por ejemplo, en la tradición kantiana, se define a la persona como aquel sujeto cuyas acciones le son imputables, es decir, aquel sujeto que consideramos «responsable» de sus acciones. Refiriéndose a esta misma idea, Muguerza señala que si alguien rechazase su condición de responsable estaría equiparándose a una mera cosa y, por tanto, dimitiendo de su condición de persona: «estaría renunciando a la humana carga de ser dueño de [sus] actos» (Muguerza, 1991: 19 y 20). De modo que con el concepto de responsabilidad se estaría aludiendo a la posición del ser humano como agente (sujeto activo) en el mundo que le rodea.

Pero las alusiones a la responsabilidad resultan fundamentales también desde el otro extremo de las teorías éticas, en las llamadas éticas consecuencialistas, donde las referencias a la responsabilidad ocupan también un lugar central, aunque en un sentido distinto: para llamar la atención precisamente sobre la relevancia moral de las consecuencias de nuestras acciones. Max Weber (1981: 163 y ss.) consagró la contraposición entre la ética de las convicciones (deontologista) y la ética de las responsabilidades (consecuencialista). La llamada «ética de la responsabilidad» pone en primer plano la relevancia de las consecuencias $^{8}$. En este sentido se ha señalado que las «responsabilidades» (entendidas como las exigencias de que se produzcan ciertos resultados) serían para los consecuencialistas lo que los «deberes» son para los deontologistas (Goodin, 1995: 81).

Aunando ambas intuiciones, podemos considerar que el «sujeto responsable» es el que se hace cargo o responde de algo, y lo hace desde una doble perspectiva: ex ante, es el que tiene la capacidad o el poder (y/o deber) de dar lugar a un determinado estado de cosas (o de evitar su producción); y ex post, es el que asume o debe asumir las consecuencias de la producción de algún estado de cosas (bien sea en términos de sanción o de reparación). En este sentido, hace ya algunos años, Garzón Valdés (1996) distinguió dos posibles usos de los juicios de atribución de responsabilidad a los sujetos (juicios con la estructura: «X es responsable de Y»), cada uno de los cuales sería formulado desde una distinta perspectiva temporal respecto a los estados de cosas a valorar y a los que propuso llamar enunciados de responsabilidad personales «prospectivos» y «retrospectivos». Los primeros serían los que se refieren a un estado de cosas futuro y en ese sentido se formulan desde una perspectiva ex ante respecto a dicho estado de cosas; mientras que los segundos se refieren a un estado de cosas pasado y en ese sentido se formulan desde una perspectiva ex post respecto al mismo. Ahora bien, conviene percatarse de que hay una asimetría en el contenido que suele dársele (al menos en el ámbito jurídico) a la «Y» en los casos en los que se refiere al pasado y en los que lo hace al futuro. En la responsabilidad prospectiva se trata de un fin u objetivo a perseguir, y en ese sentido la $Y$ representa necesariamente un estado de cosas valorado positivamente por el sistema normativo de referencia («el profesor es el responsable del aprendizaje de los alumnos», «los padres son los responsables del bienestar de los hijos»). Mientras que, en la responsabilidad retrospectiva, la Y representa un estado de cosas valorado negativamente por la práctica normativa de referencia y que normalmente se traduce en la producción de un daño o la lesión de un bien digno de protección según dicha práctica ${ }^{9}$ («Fulano es responsable del asesinato de Mengano», «el gerente de la Universidad es el responsable del desfalco en ella cometido»).

En los juicios prospectivos de atribución de responsabilidad estaríamos usando el término «responsabilidad» para relacionar a un sujeto con un determinado fin u objetivo (un estado de cosas futuro), atribu-

7 La referencia clásica en el ámbito jurídico para el análisis de los distintos sentidos de responsabilidad la encontramos en HART (1968: 211 y ss.).

8 Como es el caso, por ejemplo, de HANS JONAS (1995) quien pretende desarrollar una ética para la «era tecnológica» basada precisamente en lo que denomina el «principio de responsabilidad», que pretende ser una llamada de atención sobre el peligro de las posibles consecuencias del progreso tecnológico y de las acciones colectivas.

9 Obviamente nada impediría realizar juicios de atribución de "responsabilidad retrospectiva» por estados de cosas valorados positivamente y así, podríamos decir, por ejemplo: «La ONG "Proactiva Open Arms" es responsable de la salvación de cientos de refugiados»; pero rara vez hablamos así, y en estos casos utilizamos más el término «mérito» que el de «responsabilidad». Quizás ello se deba a que en la responsabilidad retrospectiva nos encontramos, junto al aspecto valorativo, también una reacción del sistema normativo que se suele traducir en la sancionabilidad o exigibilidad de cierta reparación. 
yéndole deberes relacionados con la persecución de dicho fin, como por ejemplo cuando decimos que «el ingeniero es el responsable del buen mantenimiento de la red de carreteras bajo su cargo». Pero es importante darse cuenta de que estos juicios no sólo tienen una dimensión deóntica (de atribución de deberes), sino también está presente en ellos una importante dimensión constitutiva, de atribución de ciertos status en el marco de la institución.

La mayoría de análisis jurídicos sobre la responsabilidad personal de los empleados públicos ${ }^{10}$ suelen realizarse desde una perspectiva ex post o retrospectiva; se preocupan por determinar cuándo un funcionario o un cargo público -en el ejercicio de sus competencias- puede ser sancionado, o cuándo puede exigírsele (a él o a la institución a la que pertenece) que se haga cargo de la indemnización o reparación de determinados daños ${ }^{11}$. Encontramos así, por ejemplo, muchos trabajos sobre la responsabilidad patrimonial de la Administración o de los funcionarios; o análisis sobre las peculiaridades de los delitos cometidos por los funcionarios, o sobre su régimen disciplinario ${ }^{12}$. Sin embargo, y como ya he indicado, en este trabajo pretendo poner el foco de atención en lo que podemos considerar como una perspectiva ex ante: qué es lo que exige el correcto desempeño de una «responsabilidad» pública ${ }^{13}$. Creo que esta perspectiva resulta fundamental incluso para una buena comprensión de las responsabilidades retrospectivas que, al fin y al cabo, han de estar diseñadas para conseguir maximizar la responsabilidad de los empleados públicos; entendiendo ahora el término «responsabilidad» en un sentido valorativo, como la virtud del buen desempeño de las funciones públicas.

\section{3. ¿QUÉ TIPO DE DEBERES IMPLICA UNA RESPONSABILIDAD?}

Los juicios prospectivos de responsabilidad se corresponderían con el sentido de «responsabilidad» que Hart consideraba equivalente a «deberes propios de un rol», entendiendo «rol» en un sentido muy amplio que incluye cualquier asignación de funciones que puede ser realizada de muy diversas maneras, desde las menos institucionalizadas (un mero acuerdo de reparto de tareas), hasta las más institucionalizadas (las asignadas siguiendo reglas formalizadas de atribución de competencias en el marco de un sistema jerárquico de toma de decisiones):

«Siempre que una persona ocupe un lugar o puesto determinado en una organización social, respecto del cual se le asignan deberes específicos para promover el bienestar o impulsar de manera específica las metas o propósitos de la organización, se puede decir con corrección que esta persona es responsable del cumplimiento de estos deberes o de hacer lo necesario para satisfacerlos. Tales deberes son responsabilidad de una persona» (Hart, 1968: 212).

Hart llama la atención sobre el hecho de que no calificamos a todos los deberes que puede tener un sujeto como responsabilidades (si a un soldado se le ordena mantener limpio el campamento, diríamos -dice Hart- que tiene esa «responsabilidad»; pero si lo que se le manda es que recoja un papel del suelo, simplemente diríamos que tiene el «deber» de hacerlo, pero no que tiene esa «responsabilidad») y apunta a que la clave de la distinción quizás se encuentre (aunque confiesa no estar muy seguro de ello) en que los deberes que son calificados como responsabilidades son de un tipo relativamente complejo y amplio, que requieren

10 Aunque este trabajo se centra en el caso de los funcionarios (en un sentido amplio, que incorpora a cualquier empleado público, al margen del tipo de vinculación que mantengan con la Administración), muchas de las cosas que aquí se dicen son igualmente aplicables a autoridades, o cargos políticos que ocupan puestos de dirección en las distintas administraciones públicas. Por supuesto, hay muchas razones para un tratamiento diferenciado (estoy pensando sobre todo en el distinto tipo de discrecionalidad característica de una y otra actividad; sobre ello véase LIFANTE VIDAL (2018: 124-130), pero nos encontramos con que muchas veces las fronteras entre ambos de tipos de actividad no son tan nítidas: ¿qué tipo de cargo es el de decano de una facultad universitaria?, ¿y el de gerente de un hospital público?

11 Quizás esto sea consecuencia del predominio, en nuestra cultura jurídica, de la visión «kelseniana» del Derecho. Como es sabido, para KELSEN el elemento central del Derecho es la sanción y los ilícitos son definidos meramente como los antecedentes de las sanciones (cfr. KELSEN, 1981). Se trata, en mi opinión, de una visión deformadora del Derecho, pues se centra en un específico tipo de normas, que no da cuenta de la complejidad que encontramos en nuestras prácticas jurídicas.

12 En este mismo sentido, RIVERO ORTEGA (2020) llama la atención sobre la preeminencia de esta perspectiva «ex post». Para este autor, es fundamental que reflexionemos también sobre vías preventivas, y no sólo represivas para la mejora de la función pública.

13 El Estatuto Básico del Empleado Público (texto refundido de 2015), en sus arts. 52 a 54, sí adopta esta perspectiva, pero elige unos rótulos («código de conducta», "principios éticos» y «principios de conducta») que inducen a muchos juristas a considerarlos como no exigibles jurídicamente y a situarlos fuera del foco de atención de los análisis jurídicos. 
cuidado y atención a lo largo de un prolongado período de tiempo (frente a los deberes de corta duración o de tipo simple, relativos a hacer o no hacer algo en una ocasión particular).

En mi opinión, lo que caracterizaría a los deberes a los que nos referimos como responsabilidades en el ámbito público (caracterizado por ser un marco institucional formalizado y jerarquizado) sería el hecho de que se definen por su conexión con la promoción de determinados fines o estados de cosas considerados valiosos, que sería lo que justificaría la exigencia de prestarles «cuidado y atención»; lo que a su vez suele provocar tanto la «complejidad» como la mayor «duración» a la que hace referencia Hart. Y es precisamente esa vinculación con la promoción de ciertos fines la que determina las funciones (el status, rol o cargo) que el sujeto desempeña en el marco de la institución social de que se trate. Ocupar un determinado cargo en el marco de una institución social compromete con la persecución de los fines que justifican su propia existencia y la búsqueda del bienestar o las metas o propósitos propios de la institución; que en el caso de la Administración pública ha de estar al servicio de los intereses generales.

Por ello, las responsabilidades exigen deliberación ${ }^{14}$ : es necesario «pensar sobre ellas y hacer serios esfuerzos para satisfacerlas» (Hart, 1968: 213). Y eso es así porque pretenden la consecución de ciertos estados de cosas, y no la mera realización de acciones determinadas a priori. Nos encontramos ante situaciones que podríamos definir con el siguiente esquema « $\mathbf{X}$ debe procurar que se produzca $\mathbf{Y}$ ». Ahora bien, lo más normal es que $Y$ sea un estado de cosas que no esté completamente bajo el control del agente $\mathbf{X}^{15}$. Puede ocurrir que requiera la actuación de un agente distinto al que tiene la responsabilidad de que se produzca ese resultado. Así, por ejemplo, podemos decir que «los padres son los responsables de que sus hijos vayan a la escuela». Estas serían las llamadas por Goodin «responsabilidades de supervisión». Pero también suele ocurrir que se atribuya a un sujeto la responsabilidad de que se produzca un estado de cosas que no sea directamente el resultado de la acción de nadie en particular, aunque sí la consecuencia de una combinación de factores, entre los cuales podemos encontrar acciones de sujetos y hechos naturales (como el ejemplo del buen estado de la red de carreteras al que hacíamos referencia antes).

En este sentido, la atribución de responsabilidades prospectivas suele ir acompañada de una regulación de la conducta de una manera peculiar que consiste en no determinar de antemano la acción o acciones a realizar, sino en atribuir al destinatario (al sujeto responsable) el poder -y deber- de determinar la concreta acción a realizar para la persecución del fin o consecución del resultado a obtener ${ }^{16}$. Se trata por tanto de una regulación a través de un tipo específico de normas, a las que podemos considerar -siguiendo la caracterización que realizan Atienza y Ruiz Manero (1996)- como «normas de fin» y que se contrapondrían a las «normas de acción» ${ }^{17}$. Mientras que estas últimas califican deónticamente (como obligatoria, prohibida o permitida) una acción, las normas de fin obligan a perseguir un determinado fin, delegando en el destinatario el poder discrecional o la «responsabilidad» de seleccionar el medio óptimo para ello (aquella medida que, a la luz de las circunstancias del caso concreto y atendiendo a las posibilidades fácticas y deónticas, maximiza el fin con el menor coste posible en términos de lesión de bienes y valores protegidos). Por supuesto, el sujeto al que se le atribuye la responsabilidad y el poder discrecional a ella ligado para determinar la concreta acción a realizar, también se verá sometido a muchas otras normas que sí le impongan o prohíban acciones determinadas, y en ese sentido limiten el ámbito de su discrecionalidad.

El sujeto al que se le atribuye la responsabilidad es el que ha de decidir en cada ocasión, y a la luz de las circunstancias particulares de la misma, si ha de actuar y cómo, tarea para la cual se le exige llevar a cabo una deliberación. Como dice Dworkin (2014: 353): «la responsabilidad de función debe incluir un poder de control: algún poder para seleccionar los actos que se llevarán a cabo en el ejercicio de la función prevista». Es al sujeto responsable al que le corresponde la determinación de la conducta debida, en eso consiste precisamente la discrecionalidad que implica el ejercicio de dichas responsabilidades. Pero eso no quiere decir

14 Cfr. RICHARDSON (1999). También Goodin remarca la idea de que una responsabilidad siempre requiere preocupación por parte del sujeto, y no basta con que el estado de cosas perseguido se produzca; de modo que -en su opinión- si el estado de cosas se produjera por azar, la responsabilidad se habría desatendido (GOODIN, 1995: 81 y ss.).

15 Cfr. GONZÁLEZ LAGIER (1997), quien distingue entre estados de cosas que están completamente bajo el control del destinatario de la norma y estados de cosas que lo están sólo parcialmente.

16 Véase en este mismo sentido LARRAÑAGA (2001).

17 Dentro de las normas de fin, ATIENZA y RUIZ MANERO distinguen a su vez entre dos categorías: las reglas de fin y las directrices, que sería la proyección de su distinción entre reglas y principios y, aunque coincido con su caracterización de las directrices, no comparto totalmente la que realizan en esta obra respecto a las reglas de fin. Según esa caracterización, en el consecuente de una regla de fin nos encontraríamos la calificación deóntica de la «obtención de un estado de cosas» (ATIENZA y RUIZ MANERO, 1996: 7); mientras que, en mi opinión, sería más adecuado considerar que estas reglas obligarían a perseguir un fin. 
que la conducta por la que el sujeto opte no pueda ser controlada, ni que no pueda exigirse responsabilidad (ahora en sentido «retrospectivo») por su acción o inacción, más bien todo lo contrario: esta responsabilidad determina quién o quiénes (pues puede y suele haber responsabilidades compartidas) ${ }^{18}$ deben asumir ciertas funciones en el marco de una institución social y, por lo tanto, quiénes deberán hacerse cargo del fracaso, y en qué grado, si esas funciones no se realizan de manera adecuada. Podríamos decir entonces que son los distintos roles y funciones asignadas ex ante (la definición de las responsabilidades prospectivas) las que justificarían la exigencia de los distintos grados de responsabilidad retrospectiva (responsabilidad en el sentido de sancionabilidad).

La dinámica del cumplimiento de los deberes que implica una responsabilidad es distinta a la del cumplimiento de los deberes fijados por las normas de acción. En este último caso nos encontramos con una lógica binaria: si se ha realizado la acción debida se ha cumplido con el deber y en caso contrario se ha incumplido. Sin embargo, en el caso de los deberes vinculados a las responsabilidades la situación es distinta y opera más bien la lógica de la maximización o, mejor dicho, de la optimización ${ }^{19}$. Hay ocasiones en los que el objetivo a conseguir puede estar determinado, de modo que -al menos en principio- admitirían un cumplimiento total (aunque hay que tener en cuenta que un cumplimiento que en abstracto puede ser completamente realizable, es posible que, en la práctica y a la luz de los recursos disponibles, sólo pueda ser cumplido en cierto grado); sin embargo en la mayoría de las ocasiones nos encontraremos con objetivos que apuntan a un estado ideal que nunca puede ser completamente obtenido, sino sólo por aproximación; de modo que el sujeto responsable nunca puede cumplir completamente con su responsabilidad. En estos casos el esquema de la norma no sería tanto "X debe procurar que se produzca $Y$ (un estado de cosas determinado)», como «X debe velar por $Y$ (un fin valioso)» ${ }^{20}$. Ejemplo de este segundo tipo sería la responsabilidad de los profesores por el aprendizaje de los alumnos. Este fin no sólo puede lograrse en distintos grados, sino que una vez que se obtiene un determinado nivel de satisfacción de los mismos, la responsabilidad no se agota, sino que exigiría seguir avanzando en el logro del objetivo (podríamos decir que el objetivo a alcanzar se va desplazando). Por lo tanto, para evaluar el grado de cumplimiento de una responsabilidad, habrá que tener en cuenta no solo el grado de cumplimiento del fin perseguido, sino también el punto de partida, los medios disponibles, etc.

\section{LA EVALUACIÓN DEL DESEMPEÑO DE LAS RESPONSABILIDADES PÚBLICAS}

Como ya he señalado, creo que resulta inadecuado reducir el análisis del desempeño de las responsabilidades en general, y las relativas al ejercicio de funciones públicas en particular, a la cuestión de cuándo puede o debe sancionarse u obligar a indemnizar al sujeto que desempeña dicha responsabilidad. Necesitamos reflexionar también sobre qué es lo que exige el buen desempeño de estas funciones públicas para poder así definir también su contrario: el incumplimiento en este ámbito. La atribución jurídica de responsabilidades retrospectivas (sanciones penales o disciplinarias, obligaciones de indemnizar...) a los servidores públicos es sólo un instrumento para favorecer el buen desempeño de sus funciones, de modo que su diseño ha de estar dirigido al logro de dicho fin; fin que ha de poder definirse de manera independiente a la mera ausencia de sanciones o indemnizaciones (dicho de otro modo: el buen «servidor público» no es simplemente el que no da lugar a sanciones o indemnizaciones, sino aquel que sirve del mejor modo a los intereses generales por los que ha de velar).

Pues bien, pretendo ahora plantear algunas ideas sobre qué es lo que exigiría el «buen» desempeño de las responsabilidades atribuidas en el ejercicio de funciones públicas. Tal y como he intentado mostrar en el apartado anterior, al vincularse la regulación de las responsabilidades prospectivas a las normas de fin, lo que exige el ejercicio de una responsabilidad nunca podrá reducirse al mero cumplimiento de un catálogo cerrado de deberes predeterminados en reglas de acción. Pensemos, por ejemplo, en cómo regula la legislación española la responsabilidad en la tramitación administrativa:

18 Cfr. GOODIN (1995: 100 y ss.).

19 Opto por hablar de «optimización», en lugar de «maximización», pues no se trata sólo de conseguir el máximo de ese objetivo, sino hacerlo afectando lo menos posibles a otros bienes y valores protegidos por el sistema normativo de referencia. Aunque el resultado obtenido sea el mismo, la selección de uno u otro medio puede no ser indiferente para el sistema.

20 GOODIN (1995: 85-86) habla de «responsabilidades de objetivo fijo» para referirse a las primeras y de «responsabilidades de objetivo variable» [receding-targets] para las segundas. 
«los titulares de las unidades administrativas y el personal al servicio de las Administraciones Públicas que tuviesen a su cargo la resolución o el despacho de los asuntos, serán responsables directos de su tramitación y adoptarán las medidas oportunas para remover los obstáculos que impidan, dificulten o retrasen el ejercicio pleno de los derechos de los interesados o el respeto a sus intereses legítimos, disponiendo lo necesario para evitar y eliminar toda anormalidad en la tramitación de procedimientos» (art. 20 de la Ley de 1 de octubre de 2015 de Procedimiento administrativo común de las administraciones públicas).

No hay manera de traducir en abstracto y a priori este enunciado a un conjunto de acciones prohibidas y acciones obligatorias que agote el cumplimiento de la responsabilidad del gestor. Las medidas habrán de ser determinadas a la luz de las circunstancias de los concretos «obstáculos» que vayan apareciendo. Por supuesto esa norma se irá concretando, en los distintos procedimientos, en una serie de reglas que vayan estableciendo deberes específicos, pero eso no evitará que los «responsables del asunto» tengan que seguir prestando atención a las nuevas situaciones que se puedan plantear, y tengan que deliberar para encontrar la medida más adecuada para cumplir esos fines (ejercicio de los derechos de los interesados y respeto por los intereses legítimos) a la luz de los recursos disponibles.

De este modo, y si pasamos ahora a ver la cuestión en negativo, nos encontramos con que «incumplir» con lo que nos exige una responsabilidad puede ser, por tanto, algo distinto a incumplir un concreto deber de acción prefijado en una regla de acción ${ }^{21}$. Las responsabilidades se atribuyen para conseguir ciertos fines considerados valiosos, y a su vez dichos fines han de ser perseguidos de la manera más coherente con los principios y valores subyacentes a la práctica normativa ${ }^{22}$. Al mismo tiempo, ello muestra la insuficiencia de las respuestas que podemos considerar clásicas para la lucha contra el mal desempeño de las funciones públicas ${ }^{23}$ : el Derecho sancionatorio (penal o disciplinario), la atribución de responsabilidades patrimoniales, o la redacción de catálogos de deberes muy pormenorizados (pensemos en lo que se ha traducido la «calidad» en la función docente: cumplimiento burocratizado de una multitud heterogénea de estándares todos ellos «cuantificables», pero poco o nada relacionados con la calidad docente).

Por supuesto que hay muchas conductas «irresponsables» consistentes precisamente en incumplimientos de deberes de acción fijados de antemano en una regla, y que serían por tanto -por utilizar la categoría de Atienza y Ruiz Manero- «ilícitos típicos», pero también nos encontramos ante casos que no encajarían en esta categoría y que serían por tanto «ilícitos atípicos» ${ }^{24}$ : pensemos en todas las conductas que, sin violar ninguna regla de acción, pongan en peligro el bien o el fin que la responsabilidad atribuida obliga a perseguir. Dicho de otro modo: para enjuiciar el desempeño de una responsabilidad en el ejercicio de funciones públicas debemos ir más allá del nivel de las reglas de acción de un determinado sistema. Así, por ejemplo, podemos considerar que incumplió con su responsabilidad el cónsul español en Boston que, tras el atentado durante el maratón de 2013, cerró la delegación «a la hora habitual»: dos horas después del atentado ${ }^{25}$.

Como hemos visto, la atribución de responsabilidades vinculadas el ejercicio de funciones públicas suele conllevar la atribución de poderes discrecionales que requerirán deliberación por parte del sujeto responsable para determinar la medida a adoptar y que habrá de ser aquélla que, a la luz de las circunstancias del caso, maximice los fines y valores a desarrollar. Es decir, entre las razones que han de operar para tomar la decisión nos encontramos con razones finalistas ${ }^{26}$, de modo que hemos de tener en cuenta las peculiaridades con las que éstas operan. Siguiendo a Summers (1978), podemos decir que son razones de carácter fáctico, están orientadas hacia el futuro y presentan un aspecto de graduabilidad, al que ya antes hemos hecho referencia. Las dos primeras características implican que estas razones presuponen una relación causal que es en la que se basa la predicción. Ello puede hacernos considerar que, en el momento de la toma de

21 Cfr., en este mismo sentido, JONAS (1995: 167 y ss.).

22 ATIENZA y RUIZ MANERO (2000) definen esta categoría como aquellos como supuestos de conducta contraria no a reglas sino a principios. En ella incardinan las figuras del abuso de derecho, el fraude de ley y la desviación de poder.

23 Cfr. ROLDÁN XOPA (2013).

24 Incluso me atrevería a decir que hay casos en los que, incumpliendo un determinado deber impuesto en una regla de acción, no se incumple sin embargo con la responsabilidad: un funcionario puede en un caso concreto incumplir un plazo al que está sometido en cierta tramitación y no por ello consideraríamos sin más que ha desempeñado mal su responsabilidad (aunque ese juicio puede no evitar ciertas consecuencias previstas para tal incumplimiento).

25 http://internacional.elpais.com/internacional/2013/04/16/actualidad/1366117225_762812.html.

26 SUMMERS (1978), a quien sigo en este punto, considera a las razones de fin como un tipo (junto a las razones de corrección) de razones sustantivas. En su opinión para entender el razonamiento jurídico necesitamos tanto la categoría de razones sustantivas, como la de razones autoritativas y la de razones institucionales. Sobre esta tipología puede verse ATIENZA (2013: 284-285 y 315-318). 
decisión, una razón finalista podía tener mucha fuerza a favor de una determinada actuación, aunque resulte que no se llegó a conseguir el fin previsto (o en la medida prevista): es decir, puede que nos encontremos ante una actuación correcta, pero que a la larga (por hechos imprevisibles o circunstancias imposibles de conocer en el momento de actuar) no dé el resultado previsible. Pensemos en algunas de las medidas adoptadas para luchar contra la propagación de la Covid-19 al inicio de la pandemia, cuando la información existente sobre sus vías de contagio era aún muy deficiente, y que acabaron resultando contraproducentes. En este sentido, a la hora de evaluar el grado de cumplimiento de una responsabilidad podemos distinguir dos dimensiones: una objetiva, centrada simplemente en los resultados obtenidos (y que pueden depender de factores ajenos al sujeto, tales como los medios o el conocimiento disponible); y otra subjetiva, centrada en el cumplimiento de los deberes por parte del sujeto y que dependerá de la calidad de la deliberación que le lleva a adoptar una concreta medida y que es la que justificará la realización de reproches personales al sujeto por considerar que ha incumplido la norma de fin que los regula ${ }^{27}$. Por supuesto lo que aquí nos interesa es esta segunda dimensión, la subjetiva.

Antes he señalado que los enunciados de atribución de responsabilidad cumplen al mismo tiempo una función deóntica o regulativa (de atribución de deberes $u$ otras posiciones jurídicas) y una función constitutiva (atribución de status en el marco de la institución). Pues bien, ahora se trata de poner de manifiesto que estos juicios también pueden cumplir una importante función evaluativa. Decir que alguien actuó responsablemente en una determinada ocasión implica llevar a cabo un juicio valorativo positivo frente a dicha acción, juicio que se realiza a la luz de los valores de la práctica normativa en la que nos encontremos; y correlativamente calificar de irresponsable una actuación implica una valoración negativa de la misma. Cuando predicamos este concepto valorativo de responsabilidad del carácter de un individuo («El sujeto $X$ es responsable»), estaríamos haciendo referencia a la responsabilidad entendida como una virtud (que puede ser de distinta índole atendiendo al ámbito en el que la predicamos). Solemos decir que una «persona responsable» es aquélla que pone cuidado y atención en lo que hace, y que dicha atención ha de estar encaminada precisamente a preocuparse por las consecuencias de sus acciones, ha de procurar obtener las «mejores» consecuencias. Ahora bien, esta evaluación de las consecuencias (su consideración como mejores o peores) será relativa a los fines o valores que el sujeto responsable haya de perseguir en el caso en cuestión. Por otro lado, al poner el acento en el aspecto de promoción de fines y valores, la virtud de la responsabilidad suele vincularse con la idea tanto de coherencia como de integridad: una persona que actúa de forma íntegra sería aquélla que deriva sus acciones y creencias de un grupo de valores esenciales (Villoria, 2012: 108). Y actuar «responsablemente» sería equivalente a actuar de forma coherente con esos valores, creencias y principios ${ }^{28}$.

El desempeño adecuado de las responsabilidades públicas, aquellas encomendadas en el marco de una práctica normativa a ciertos sujetos para que procuren la consecución de objetivos en beneficio de intereses generales, exigirá que las acciones del sujeto resulten coherentes con los fines y valores que pretende desarrollar la institución en la que se incardina la concreta función objeto de responsabilidad. Se trata de actuaciones que han de gestionar no intereses propios del sujeto que actúa, sino intereses ajenos (en el

27 La distinción entre estas dos dimensiones quizás ayude a entender la sorprendente (y en mi opinión injustificada) sentencia del Tribunal Supremo español, que estima parcialmente un recurso contra la inactividad del Ministerio de Sanidad, por haber generado una lesión de los derechos fundamentales a la protección de la salud y la vida de los profesionales sanitarios, dado que, al inicio de la pandemia, carecieron de los medios de protección necesarios contra la Covid-19 (STS 1271/2020, de 8 de octubre). El carácter sorpresivo de esta conclusión estriba en que la sentencia había argumentado que los medios disponibles en aquel momento a nivel mundial eran claramente insuficientes para que la Administración hubiera podido proteger adecuadamente a los sanitarios del riesgo de contagio. Lo que la sentencia parece indicar, al estimar parcialmente el recurso, es simplemente que el resultado obtenido no es acorde con los fines perseguidos por el art. 12.4 del Real Decreto 463/2020 (por el que se declaró el Estado de Alarma). Dicho artículo establece que se deberá garantizar «la mejor distribución en el territorio de todos los medios técnicos y personales, de acuerdo con las necesidades que se pongan de manifiesto en la gestión de esta crisis sanitaria». La sentencia parece olvidar que calificar a una distribución de medios como mejor o peor ha de hacerse atendiendo a las posibilidades de acción, medios disponibles, etc. con los que contaba la Administración en ese momento, y no exclusivamente estableciendo que el fin valioso perseguido por dicha distribución (la satisfacción de las necesidades de protección para los sanitarios) no se consiguió. Y el propio TS establece que dicho fin era inalcanzable para la Administración en aquel momento, dado que no había ningún curso de acción posible para evitar o mitigar ese riesgo. En mi opinión no hubo, por tanto, incumplimiento de dicha norma de fin y no se entiende, por tanto, que la sentencia declare que se ha producido una «lesión» de esos derechos fundamentales atribuible a la actuación (en este caso, omisión) de la Administración (en este caso, del Ministerio de Sanidad).

28 En este sentido, DWORKIN sostiene que una persona es responsable es la que adopta una epistemología «interpretativa»: alguien es responsable en la medida en que sus diversas interpretaciones concretas alcanzan una integridad global, de manera que cada una de ellas respalda a las demás en una red de valor a la que presta adhesión (DWORKIN, 2014: 132). 
ámbito de la Administración pública: intereses generales), por lo que el concepto de representación puede resultarnos aquí de utilidad: el deber del representante se define atendiendo precisamente a la maximización de los intereses de aquello que se representa y que puede ser no sólo uno o varios individuos, sino también una institución, o intereses colectivos ${ }^{29}$. En este sentido, los fines a perseguir y los valores por los que velar, le vienen -por así decir-impuestos al sujeto que ostenta la responsabilidad al que se le exigirá «lealtad» a los mismos.

\section{UN CATÁLOGO DE «VICIOS» DE LA ADMINISTRACIÓN PÚBLICA: CORRUPCIÓN, FORMALISMO, DESIDIA E INCOMPETENCIA}

Hemos visto que el correcto desempeño de una responsabilidad pública exige prestar atención a los fines y valores por los que ha de velar en el desempeño de su función, adoptando la medida más adecuada para alcanzar esos fines a la luz de las circunstancias del caso concreto. Pues bien, dependiendo de cuáles de esas exigencias se desatiendan, podemos distinguir varios tipos de incumplimiento de una responsabilidad $^{30}$ : 1. aquellos casos en los que el sujeto actúa persiguiendo fines distintos a aquéllos por los que ha de velar en el desempeño de su función pública (serían supuestos de «deslealtad» con los principios expresivos de los fines que han de regir su actuación); 2. aquellos casos en los que sólo se persiguen algunos de esos fines, desentendiendo del resto (serían supuestos de compartimentación o deficiente integridad o coherencia entre los diferentes principios por los que el sujeto ha de velar en su actuación); 3 . aquellos casos en los que el sujeto no presta la debida atención a la determinación de la medida adecuada para la consecución de los fines por los que ha de velar (serían supuestos de desidia o falta de voluntad); y 4. aquellos casos en los que el sujeto selecciona, por incompetencia, medios inadecuados para la persecución de los fines encomendados.

Obviamente esta tipología no pretende ser una clasificación exhaustiva ni excluyente de los distintos casos de incumplimiento, pues en la práctica pueden y suelen darse conjuntamente, sino que la misma haría referencia a algo así como a «tipos ideales» de incumplimiento, cada uno de los cuales estaría típicamente conectado con alguno de los grandes males, o vicios, de la Administración Pública: la corrupción, el formalismo, la desidia y la incompetencia. Creo que esta tipología puede resultar útil en la medida en que pueda ayudarnos a pensar sobre los distintos mecanismos para evitar incumplimientos y promover, en cambio, conductas responsables.

El primer supuesto de incumplimiento sería aquel en el que el sujeto que ostenta la responsabilidad no actúa de acuerdo con los principios (fines o valores) a los que debe lealtad: la medida adoptada por el sujeto no persigue promover los fines y valores que han de guiar el ejercicio de su función, sino objetivos distintos. Recordemos que el servidor público no gestiona sus propios intereses, sino intereses públicos definidos normativamente, y es por éstos por los que ha de velar en su actuación. En este sentido incumpliría su responsabilidad quien no actuara guiado por la defensa de los intereses públicos, sino por sus propios intereses o por otros intereses particulares. La mayoría de casos que usualmente consideramos como "corrupción» se incardinarían en estos supuestos de deslealtad a los principios que han de regir la actuación del servidor público. No es fácil ofrecer una definición omnicomprensiva que incluya todos aquellas actuaciones que calificaríamos como corruptas ${ }^{31}$, pero creo que la clave se encuentra precisamente en la sustitución de los intereses generales por los que un sujeto ha de velar en función de su cargo por otros intereses particulares (sean propios o ajenos) ${ }^{32}$. El caso paradigmático de conducta corrupta de un servidor público sería el que utiliza su cargo para enriquecerse, o para favorecer a amigos o allegados. Aquí nos encontramos desde los

29 En otros trabajos (véase, por todos, LIFANTE VIDAL, 2018, cap. 1) me he ocupado de caracterizar tres tipos de representación práctica: la representación individual, la colectiva y la institucional. Allí defendí que la relación representativa implica siempre la obligación de actuar «en interés de» los representados.

30 Esta clasificación está inspirada (de manera bastante libre) en los tres modos de actuar irresponsablemente que DWORKIN señala para la responsabilidad ética: aquélla que tenemos respecto a cómo vivir nuestra propia vida. El primero sería la falta de sinceridad o compromiso con los principios; el segundo, la desconexión entre los principios abstractos aceptados y las acciones realizadas; y el tercero, la esquizofrenia moral o compartimentación entre los distintos principios (DWORKIN, $2014: 135$ y ss.).

31 Por supuesto mi interés aquí es un concepto amplio de corrupción, que no incluya sólo los casos más graves, que serían los tipificados penalmente como delitos. En estos casos, por supuesto, el ordenamiento sí incorpora una regla de acción específica que prohíbe la realización de dicha conducta tipificada como delito.

32 Me aparto así, de una definición más estricta de corrupción, como la que adoptan GARZÓN VALDÉS (2004) y VÁZQUEZ (2007). Sobre mis discrepancias conceptuales (por otro lado, muy menores) con estos autores, puede verse (LIFANTE VIDAL, 2017). 
casos considerados como "corrupción de alta intensidad», como el amaño de una contratación pública a cambio de una comisión; hasta los casos que suelen calificarse como «corrupción de baja intensidad», como el de un profesor que aprueba al hijo de un colega para mantener una cómoda relación laboral, o el del médico que receta una determinada marca de medicamentos no por sus cualidades sino por las ventajas que le ofrece el correspondiente visitador médico. Pero alguien podría también apartarse de los fines a los que ha de servir no por razones basadas en el interés (conseguir un beneficio indebido), sino, por ejemplo, por adhesión a otros principios distintos a los que el Derecho establece para su ámbito de actuación; de modo que sería su compromiso con esos principios o valores ajenos a los impuestos por el Derecho los que le llevarían a apartarse de la maximización de los fines que ha de perseguir en cumplimiento de su responsabilidad ${ }^{33}$. Imaginemos el caso de un rector de una universidad pública (en un Estado social de Derecho) que estuviera convencido de las ventajas de la competencia y libre mercado en materia educativa, y que desempeñara su cargo orientado a maximizar este fin, desentendiéndose de la calidad de la educación pública. Si consideramos que su actuación no pretende la obtención de beneficio alguno (ni para sí ni para allegados con intereses en la educación privada), este caso quizás no sería calificado en sentido estricto como «corrupción», pero se trataría igualmente de un supuesto de incumplimiento de una responsabilidad pública por deslealtad a los fines y valores que ha de perseguir.

El segundo supuesto de incumplimiento sería el de aquellos casos en los que sólo se persiguen algunos de los diferentes fines por los que se ha de velar en el ejercicio de una responsabilidad, desentendiendo del resto; serían por tanto supuestos en los que se produce una compartimentación o deficiente integridad o coherencia entre los diferentes principios que han de regir la actuación del sujeto. Normalmente en el desempeño de las responsabilidades públicas, los funcionarios no sólo han de velar por un fin o valor determinado, sino por varios al mismo tiempo; de modo que este sujeto se encuentra con que debe lealtad a distintos principios que pueden entrar en colisión entre sí. La actuación responsable implicará que el sujeto lleve a cabo la necesaria deliberación para determinar qué concepción o especificación de esos principios es la que resulta más coherente con el conjunto de los valores; por el contrario, la actuación irresponsable será la de quien no lleva a cabo esta tarea de integración de los distintos principios relevantes. Puede que el sujeto no lo intente en absoluto (por pura pereza) y opte por uno de ellos sin tomar el otro en cuenta; o que lo intente, pero lo haga de manera deficiente porque no encuentre una concepción y especificación de esos principios que resulte coherente con todos ellos y que pueda aceptar, optando entonces por una «compartimentación» de la vigencia de esos principios. Para actuar responsablemente es necesario, por tanto, no ser sólo leal, sino también diligente y perseverante (prestar aplicación, celo y esfuerzo en el desempeño de la función). Creo que esta compartimentación sería la que está detrás de muchas de las actuaciones que consideraríamos ejemplos de conducta "formalista», en las que el sujeto se preocupa solo por uno de los principios que han de regir su actuación (la certeza o predecibilidad), olvidando los otros que persiguen la promoción de ciertos valores sustantivos a los que también debe lealtad ${ }^{34}$. Muchos de estos casos de «burócratas formalistas» se incardinarían en los supuestos de anomia que Merton (2002: 229 y ss.) caracterizaba como conducta ritualista, en los que se abandonan los objetivos y se respetan casi de manera compulsiva los medios institucionales, fundamentalmente los procedimientos, anteponiendo las formalidades más nimias a la consecución de cualquier objetivo valioso perseguido ${ }^{35}$. Pensemos, por ejemplo, en un burócrata que se empeña en aplicar rigurosamente un procedimiento, diseñado a partir de unas determinadas situaciones típicas, a otras situaciones claramente distintas a aquéllas, sin llevar a cabo la necesaria adaptación para la consecución de los fines valiosos perseguidos por el procedimiento. Pensemos en un protocolo para evitar

33 En este punto puede resultar útil el análisis de GARCíA VILLEGAS (2011) a propósito del fenómeno del incumplimiento del Derecho (en general, y no sólo para los funcionarios). Este autor distingue tres «tipos ideales» de mentalidades incumplidoras: los vivos, los rebeldes y los arrogantes (a los que se les unirían los taimados y los déspotas, que serían modalidades intermedias). Los tres se ubicarían en este primer tipo de incumplimiento que estoy aquí caracterizado, pero no todos serían calificados como actuaciones corruptas. Los «vivos» serían los que incumplen para maximizar el interés propio; los «rebeldes» los que incumplen para defenderse de normas consideradas ilegítimas; y los «arrogantes», los que incumplen por considerar que hay valores que prevalecen a los impuestos por las normas.

34 También los supuestos que -desde el otro extremo- suelen calificarse como «activismo» pueden ser vistos como ejemplos de esta «compartimentación» de los principios (en este caso por dejar fuera de la ponderación al valor de la certeza). En el texto me refiero fundamentalmente a las conductas formalistas porque, en el ámbito de los servidores públicos o funcionarios en general, éstas suelen ser un tipo de conductas «irresponsables» mucho más generalizadas.

35 Así, por ejemplo, en marzo de 2015 el Ministerio de economía dejó sin financiación pública a prestigiosos grupos de investigación por lo que consideró «errores de forma no subsanables»: presentar un curriculum de seis páginas cuando el máximo establecido eran cuatro (http://elpais.com/elpais/2015/03/25/ciencia/1427302389_543128.html). 
el contagio de la Covid-19 en el servicio de préstamo de libros de una biblioteca, según el cual los libros utilizados deben permanecer un período de tiempo en cuarentena antes de volver a circulación; obviamente dicho protocolo está pensado para las situaciones en las que el usuario que quiere sacar en préstamo un libro es distinto de la persona que acaba de consultar el libro en la sala; aplicar la cuarentena también a los casos en los que se trata de la misma persona sería un claro ejemplo de formalismo.

El tercer tipo de incumplimiento se daría cuando el funcionario no presta la debida atención a la determinación de la medida adecuada para la consecución de los fines por los que ha de velar. Ya no se trata de los casos en que un sujeto persiga fines distintos a los que debe lealtad por su cargo, o se olvide de alguno de los fines por los que ha de velar; sino de aquellos otros casos en los que el sujeto se despreocupa de su responsabilidad a la hora de definir cuál debería ser su actuación (aquella que optimiza los fines y valores por los que ha de velar), por desidia o cesión frente a influencias externas que acaban llevando al funcionario a optar por conductas que podríamos calificar de «acomodaticias». En el marco de instituciones jerárquicamente estructuradas (en las que los distintos roles desempeñados definen de manera muy señalada relaciones de autoridad, coordinación o vigilancia entre distintos sujetos) es usual que se acaben diseñando de manera informal procedimientos y códigos de conducta que conforman el tipo de acciones que un sujeto puede emprender, y que la actuación fuera de este contexto pueda implicar cierto coste para un sujeto ${ }^{36}$ (no promoción, pérdida de prestigio, o simple incomodidad en la institución). De modo que estos factores, que acaban generando informalmente una cierta «cultura organizacional», pueden fácilmente motivar a los individuos a someterse, generando cierto grado de servilismo, cierta inercia acomodaticia que hace que el sujeto abandone su responsabilidad; es decir, que se plantee siquiera qué es lo que él mismo considera la mejor manera de desempeñar las funciones que tiene encomendadas a la luz de los principios y valores a los que debe adhesión, sino que opte por realizar (por acción u omisión) lo que le resulta más cómodo: dejarse llevar por la rutina ${ }^{37}$. Pensemos en el funcionario que sospecha de la irregularidad de una contratación, pero que ante las dificultades de que una hipotética denuncia salga adelante, decidir mirar hacia otro lado; o el profesor de una universidad pública que decide no oponerse públicamente a un plan de estudios que considera nefasto... Estos supuestos de desidia, o «conductas acomodaticias», nos muestran que la actuación responsable no exige sólo lealtad a los principios y diligencia, sino también otras virtudes -como la valentía o la autonomía intelectual- para llevar a la práctica aquello que se cree justificado.

Por último, nos encontramos con aquellos casos en los que el funcionario selecciona, negligentemente, medidas que resultan inadecuadas para la persecución de los fines encomendados. Aunque un sujeto se preocupe efectivamente por los fines por los que ha de velar en el desempeño de su cargo, es posible que se equivoque en su opción y adopte una medida inadecuada (a la luz de la información y los medios disponibles) para la persecución de dichos fines: la actuación a la que su deliberación le conduce no es la que objetivamente sirve mejor a los intereses por los que ha de velar. Se trata de un tipo de incumplimiento causado por la incompetencia del sujeto para desempeñar adecuadamente su función. En este sentido, hemos de ser conscientes de que para el óptimo desempeño de una función pública se requiere no sólo lealtad a los fines institucionales y preocupación y celo en el desempeño del cargo, sino también poseer ciertas capacidades intelectuales y otras virtudes como la phronesis o sabiduría práctica, apertura de mente, etc.

\section{ALGUNAS IDEAS -MUY PRELIMINARES- PARA LA MEJORA DEL DESEMPEÑO PÚBLICO}

Hemos visto que algunos casos de mal desempeño de una responsabilidad pública tienen que ver con que la actuación del sujeto no vela por los intereses a los que ha de servir (sustituyéndolos por otros, u ocupándose sólo de algunos de ellos), mientras que otros se explican por la desidia o falta de capacidad del sujeto para desempeñar adecuadamente sus funciones. Las estrategias adecuadas para luchar contra cada uno de estos tipos de incumplimientos pueden ser muy distintas; la mayoría de los análisis se centran exclusivamente en la lucha contra la corrupción (quizás por considerarla en términos subjetivos la más

36 Cfr. IGLESIAS VILA (2003: 14).

37 GARCÍA VILLEGAS (2011: 175) señala que el sujeto incumplidor no siempre responde a una racionalidad bien sea valorativa o instrumental. Hay que tener en cuenta, nos recuerda este autor, que muchas veces operan otras normas (no jurídicas) a las que el sujeto se adhiere no necesariamente por interés o por convicción, sino por la acción de lo que (utilizando la terminología de Bourdieu) denomina «habitus». Este «habitus» (o rutina) tiene algo de irreflexivo y por lo tanto de abandono de lo que la responsabilidad exigiría: prestar atención a la situación y preocuparse por la consecución de los fines perseguidos. 
reprochable), pero si queremos que la Administración Pública sirva eficazmente a los intereses generales necesitamos diseñar también estrategias que minimicen el formalismo, la desidia o la incompetencia. $Y$, en este sentido, creo que un primer -aunque modesto- paso es precisamente sacarlas a la luz como conductas contrarias a lo que el Derecho exige.

A la hora de diseñar frenos o mecanismos de lucha contra los vicios de la Administración nos encontramos con dos posibles perspectivas. La primera sería la que adopta el punto de vista del individuo (el funcionario que ha de actuar y que puede llevar a cabo o bien actuaciones responsables, o bien actuaciones corruptas, formalistas, acomodaticias o negligentes) y la segunda sería la que adopta el punto de vista institucional (los diseños institucionales que pueden favorecer, dificultar o impedir la aparición de dichas conductas). Un buen planteamiento del problema presupone no olvidarse de ninguna de estas dos perspectivas y, sobre todo, de las importantes interacciones que pueden producirse entre ambas.

Es necesario comenzar remarcando que el funcionario que incumple su responsabilidad lo hace o bien porque posee una «motivación» que le impulsa a dicho acto (le resulta ventajoso desde alguna perspectiva, aunque sea la pura comodidad de no aplicar la diligencia debida); o bien porque se ha generado en la institución una rutina de actuación irresponsable al que el sujeto se adhiere, no necesariamente por interés o por convicción, sino de una manera irreflexiva. Necesitamos, por tanto, pensar mecanismos o diseños institucionales que puedan ayudarnos a contrarrestar o eliminar las motivaciones espurias, a incrementar la diligencia, o a combatir la aparición de hábitos o inercias nocivas.

En primer lugar, parece indispensable contar con un buen diseño de responsabilidades personales retrospectivas (sanciones u obligaciones de indemnizar) que contrarresten las posibles ventajas que puedan motivar al funcionario a incumplir su responsabilidad. Por supuesto, distintos tipos de incumplimientos pueden requerir distinta regulación sancionadora ${ }^{38}$. $Y$ en este punto no se trata solo, ni fundamentalmente, de que estén previstas formalmente las posibilidades de atribuir este tipo de responsabilidades personales a los funcionarios incumplidores, sino de que dichas posibilidades sean realmente efectivas ${ }^{39}$. De todos modos, aunque la falta de eficacia de las sanciones estaría efectivamente detrás de algunos tipos de incumplimiento (aquellos que estarían movidos por intereses particulares y responderían por tanto a una racionalidad meramente estratégica de cálculo de costes/beneficios), hay otros casos de incumplimientos en los que no operaría la racionalidad instrumental (como, por ejemplo, los casos de negligencia, o de conducta irreflexiva) y en los que no cabe por tanto confiar en la efectividad de las sanciones u otro tipo de consecuencias dañinas (como la obligación de asumir ciertos costes) para el incumplidor.

Junto al establecimiento de sanciones negativas existe también la posibilidad de motivar la conducta a través de incentivos económicos, o de otro tipo, que promuevan, por el contrario, las conductas responsables. Desde complementos salariales, hasta reconocimientos de méritos o posibilidades de promoción en la carrera administrativa. Me temo que muchas veces estos sistemas de incentivos se burocratizan de tal manera que parecen estar pensados para promocionar conductas formalistas y acomodaticias, en lugar de para evitarlas, y lo que acaban consiguiendo es expulsar el espíritu crítico en el desempeño de las responsabilidades públicas. Pensemos, por ejemplo, en vincular complementos de productividad meramente al número de expedientes tramitados, lo que supone un perverso incentivo para no acumular expedientes cuando ello está plenamente justificado; o vincular la calidad docente reconocida a un profesor al número de estudiantes que aprueban sus asignaturas (al margen de cualquier otra consideración), o al mero número de «contratos de adaptación curricular» que firma, etc.

38 En el ámbito de la responsabilidad de los administradores mercantiles, PAZ ARES (2003) ha propuesto diferenciar claramente entre las responsabilidades (prospectivas) por negligencia (incumplimiento de deberes de cuidado) y por deslealtad (incumplimiento de deberes de lealtad), sosteniendo que -a diferencia de lo que ocurre con las deslealtades- hay razones para ser indulgentes con las negligencias (porque en estos casos no habría conflicto de intereses entre el administrador y la empresa, sino más bien lo contrario). Ahora bien, esa "concordancia», salvo en los casos de deslealtad, entre los intereses del administrador mercantil y de la empresa (al administrador le interesa que la empresa consiga sus objetivos) me parece mucho menos obvia en el caso de los empleados públicos. Eso quizás explique que el formalismo sea un mal típico de la Administración Pública, y no tanto de la empresa privada. Quizás uno de los objetivos sea conseguir una mayor concordancia de los intereses particulares del funcionario con los intereses generales por los que ha de velar en el ejercicio de su cargo.

39 En este sentido, RIVERO ORTEGA (2020) señala que si algo falla en nuestro ordenamiento jurídico no son las posibilidades de atribuir responsabilidades (retrospectivas) personales a los empleados públicos (a diferencia de lo que ocurría con el caso de las autoridades, donde hay menos opciones), que son muchas, sino más bien su eficacia. El autor propone la simplificación en el diseño de estas responsabilidades, de manera que se elimine la creciente inseguridad jurídica en este ámbito. En este sentido propone la elaboración de un código que recoja y sistematice la atribución de responsabilidades a los empleados públicos. 
Otra posibilidad de incentivar las conductas adecuadas (y desincentivar las irresponsables) es la que apela al prestigio personal y profesional del funcionario. Para ello es fundamental incidir en la relevancia de la educación orientada a conseguir que los funcionarios desempeñen «responsablemente» (virtuosamente) sus cargos, y promover una cultura de intolerancia social frente a todos los tipos de irresponsabilidad: no sólo frente a la corrupción (que es en la que más se suele incidir), sino también frente al formalismo, la desidia o la incompetencia. Quizás en este ámbito se puedan explorar las virtualidades de la transparencia para potenciar la diligencia y el celo profesional; estoy pensando en medidas tan sencillas como sacar del anonimato a los funcionarios responsables de la adopción de algunas medidas. Muchas veces el anonimato potencia incurrir no sólo en conductas desleales, sino también acomodaticias o negligentes; mientras que, por el contrario, el interés de un funcionario por mantener su prestigio personal podría operar en sentido inverso (incrementando la diligencia) si supiera que su intervención en la adopción de cierta medida va a ser pública. Piénsese por ejemplo en el anonimato de los informantes en los procesos de acreditación de la ANECA; en poco o en nada contribuye dicho anonimato a la potenciación de conductas responsables, más bien todo lo contrario.

Una propuesta que es frecuente encontrar en los catálogos de instrumentos para luchar contra conductas irresponsables, fundamentalmente las corruptas o desleales, es la reducción (o incluso eliminación) de la discrecionalidad, que es vista como la oportunidad de generar dicho tipo de incumplimientos ${ }^{40}$. El punto de partida de este razonamiento se encuentra en la «ecuación básica de la corrupción» formulada por Klitgaard (1998) en los siguientes términos "Corrupción = Monopolio + Discrecionalidad - Rendición de cuentas», es decir, la corrupción sería una variable que es directamente proporcional al monopolio en la toma de decisiones y a la existencia de discrecionalidad, e inversamente proporcional a la rendición de cuentas. La eliminación de la discrecionalidad que se pretende con esta propuesta implicaría que la toma de decisiones por parte de la Administración estuviera guiada por reglas de acción, que predeterminen en cada situación la medida a adoptar, eliminando la deliberación que ha de realizar el sujeto a la luz de las circunstancias del caso concreto. Pero se trata -en mi opinión- de una propuesta que acaba tirando al niño con el agua sucia. La atribución de poderes discrecionales juega un papel fundamental y positivo; se trata de un fenómeno central y necesario para promover activamente ciertos fines o valores. La solución al problema de la corrupción, por tanto, no puede consistir en reglar minuciosamente todos los poderes que poseen los empleados (o autoridades) públicos para que sus decisiones sean siempre aplicaciones mecánicas de reglas preexistentes, sino más bien en fortalecer la cultura del control de la discrecionalidad. Y no sólo -aunque también-a través de los correspondientes recursos contencioso-administrativos. Muchas de las medidas que hoy se reclaman vinculadas al principio de «transparencia» van precisamente en esa línea de posibilitar un control por parte de la propia ciudadanía: se trata de dificultar la ocultación de las actuaciones irresponsables a través de una máxima publicidad de las actuaciones de las administraciones públicas y del fortalecimiento del derecho de acceso a la información pública por parte de los ciudadanos. El objetivo (como sostiene el Preámbulo de la Ley 19/2013, de transparencia, acceso a la información pública y buen gobierno) es someter a escrutinio la acción de los responsables públicos, permitiendo a los ciudadanos conocer cómo se toman las decisiones que les afectan, cómo se manejan los fondos públicos o bajo qué criterios actúan nuestras instituciones. La transparencia ha de ser vista entonces como un importante valor instrumental, en el sentido de que puede repercutir provechosamente en la calidad de nuestras instituciones.

Nos encontramos también con otro grupo de medidas que están encaminadas a evitar las ocasiones en que un determinado funcionario pueda sacar provecho del ejercicio de sus responsabilidades. Se trata de conseguir que, en el ámbito de las decisiones públicas, las razones justificativas y las razones explicativas tiendan a coincidir, minimizando las posibilidades de que puedan concurrir intereses espurios en la deliberación del funcionario. Pensemos, por ejemplo, en todas las medidas dirigidas a prevenir posibles conflictos de intereses a través del régimen de incompatibilidades, del control de «puertas giratorias», la prohibición de recibir regalos, etc.

También los diseños organizativos de las instituciones pueden ser en gran medida responsables de algunos de los males que acechan a nuestra función pública. Así, por ejemplo, ciertos diseños institucionales (ciertas divisiones de tareas administrativas, o de creación de unidades funcionales) pueden ser muy relevantes para potenciar o, por el contrario, minimizar el tipo de conductas que antes calificábamos como formalistas: cuando las responsabilidades están muy compartimentadas entre distintos órganos, se puede

40 En este sentido, véase, por ejemplo, VÁZQUEZ (2007). 
propiciar que los funcionarios pierdan de vista el proceso en su conjunto y los fines al servicio de los cuales dichos procesos están diseñados. Pensemos en una «Escuela de doctorado» cuya única función sea centralizar los expedientes de elaboración de tesis doctorales de una universidad y que a diferencia de otras facultades o escuelas no tiene ni profesorado ni alumnos; es fácil que este diseño provoque que los funcionarios de dicha unidad pierdan de vista su propia razón de ser, despreocupándose de los objetivos valiosos por los que han de velar (promover y facilitar la elaboración de tesis doctorales de calidad), convirtiendo los procedimientos burocráticos en fines en sí mismos.

Respecto a los problemas del diseño institucional general de nuestra Administración, Carles Ramió incide especialmente en el inadecuado modelo de gestión del empleo público. Este autor llama la atención sobre la importancia de contar con un proceso de selección adecuado de personal y una auténtica carrera profesional, pero también sobre la necesidad de flexibilizar la gestión de los recursos humanos, y de eliminar las fragmentaciones artificiales en que operan las administraciones públicas, fragmentaciones que cercenan las posibilidades de cooperación. Uno de los graves defectos de nuestra Administración que este autor remarca sería la ausencia de una regulación de la dirección pública profesional, ausencia que genera una cierta confusión entre el espacio político y el espacio profesional: los funcionarios que ejercen funciones directivas suelen ocupar puestos de libre designación controlados una "política partidista intrusiva». De modo que, aunque los funcionarios españoles siguen estando mayoritariamente al margen de la corrupción, la enorme dimensión del fenómeno de la corrupción de los políticos se debe en parte -en su opinión- a un endeble diseño institucional de la Administración, que dificulta enormemente la tarea de control que los funcionarios deberían llevar a cabo sobre las actuaciones de los políticos ${ }^{41}$.

Esta última reflexión puede verse como un buen ejemplo de la conexión perversa que existe entre ciertos diseños institucionales y la generación de conductas tales como la desidia o el formalismo; hay que tener en cuenta que el coste personal de ejercer responsablemente ciertas funciones puede ser en ocasiones (como en el caso del control de aquellos de los que se depende, pero también en muchos otros supuestos) muy elevado. Quizás, por eso mismo, esas conductas (a diferencia de la corrupción) son en muchas ocasiones percibidas socialmente como excusables. Pero no olvidemos que se trata también de desviaciones de lo que el principio de responsabilidad exige en el ámbito de la Administración Pública y que, como tales, la apartan de la consecución de los fines que han de perseguir.

\section{REFERENCIAS BIBLIOGRÁFICAS}

AGUILÓ REGLA, J. (2019): "En defensa del Estado constitucional de Derecho", en Doxa. Cuadernos de filosofía del Derecho, núm. 42, págs. 85-100. https://doi.org/10.14198/DOXA2019.42.04.

ATIENZA, M. (2013): Curso de argumentación jurídica. Colección Estructuras y Procesos. Serie Derecho. Madrid: Trotta.

ATIENZA, M.; RUIZ MANERO, J. (1996): Las piezas del Derecho. Barcelona: Ariel.

ATIENZA, M.; RUIZ MANERO, J. (2000): Ilícitos atípicos. Madrid: Trotta. http://dx.doi.org/10.4067/S071800122020000100192.

BARAK, A.; KAUFMANN, Y. (trad.) (1989): Judicial Discretion. New Haven; London: Yale University Press. https://doi. org/10.2307/j.ctt211qxt8.

BELL, J. (1992): "Discretionary Decision-Making: A Jurisprudential View", en HAWKINS, K. (ed.): The Uses of Discretion, págs. 89-111. Oxford: Clarendon Press.

DWORKIN, R.; PONS, H. (trad.) (2014): Justicia para erizos. México: Fondo de Cultura Económica.

GARCÍA DE ENTERRÍA, E.; FERNÁNDEZ, T. R. (1995): Curso de Derecho Administrativo. Madrid: Civitas. 5. ${ }^{a}$ ed.

GARCÍA VILLEGAS, M. (2011): "Ineficacia del Derecho e incumplimiento de reglas en América Latina", en RODRÍGUEZ GARAVITO, C. (coord.): El Derecho en América Latina. Un mapa para el pensamiento del siglo XXI, págs. 161-184 . Buenos Aires: Siglo XXI. https://doi.org/10.15174/cj.v4i2.157.

GARZÓN VALDÉS, E. (1996): "El enunciado de responsabilidad”, en Doxa. Cuadernos de filosofía del Derecho, núm. 19, págs. 259-286. https://doi.org/10.14198/DOXA1996.19.14.

GARZÓN VALDÉS, E. (2004): "Acerca de la calificación moral de la corrupción. Tan solo una propuesta”, en Isonomía, núm. 21, págs. 9-19.

GONZÁLEZ LAGIER, D. (1997): "Cómo hacer cosas con acciones (en torno a las normas de acción y a las normas de fin)", en Doxa. Cuadernos de filosofía del Derecho, núm. 20, págs. 157-175. https://doi.org/10.14198/ DOXA1997.20.05.

41 Cfr. (RAMIÓ, 2011 y 2016). 
GOODIN, R. E. (1995): Utilitarianism as a Public Philosophy. Cambridge: Cambridge University Press. https://doi. org/10.1017/CBO9780511625053.

HART, H. L. A. (1968): Punishment and Responsibility. Oxford: Clarendon Press.

IGLESIAS VILA, M. (2003): "Violencia ambiental, liberalismo y responsabilidad", en SELA (Seminario en Latinoamérica de Teoría Constitucional y Política). Papers, Paper 21. http://digitalcommons.law.yale.edu/yls_sela/21.

JONAS, H.; FERNÁNDEZ RETENAGA, J. M. (trad.) (1995): El principio de responsabilidad. Ensayo de una ética para la civilización tecnológica. Barcelona: Herder. https://doi.org/10.2307/j.ctvt9k2sz.

KELSEN, H. (1981): Teoría pura del derecho, traducción de la segunda edición en alemán por R. J. VERNENGO, México: UNAM.

KLITGAARD, R. (1998): “La cooperación internacional contra la corrupción”, en Finanzas \& Desarrollo, marzo de 1998, págs. 3-6. https://1997-2001.state.gov/global/narcotics_law/global_forum/F600espaocr.pdf.

LARRAÑAGA, P. (2001): "Responsabilidad de rol y directrices", en Doxa. Cuādernos de filosofía del Derecho, núm. 24, págs. 559-579. https://doi.org/10.14198/DOXA2001.24.21.

LIFANTE VIDAL, I. (2002): "Dos conceptos de discrecionalidad jurídica", en Doxa. Cuadernos de filosofía del Derecho, núm. 25, págs. 413-439. https://doi.org/10.14198/DOXA2002.25.12.

LIFANTE VIDAL, I. (2017): "Responsabilidad versus corrupción”, en CERDIO HERRÁN, J.; SALAZAR UGARTE, P.; LARRAÑAGA MONJARAZ, P. (coords.): Entre la libertad y la igualdad: Ensayos críticos sobre la obra de Rodolfo Vázquez, Tomo II, págs. 103-126. México: UNAM.

LIFANTE VIDAL, I. (2018): Representación y responsabilidad. México: Fontamara.

MERTON, R. K.; TORNER, F. M..; BORQUES, R. (trads.) (2002): Teoría y estructura sociales. México: Fondo de Cultura Económica.

MUGUERZA, J. (1991): "Kant y el sueño de la razón”, en THIEBAUT C. (ed.): La herencia ética de la Ilustración, págs. 9-36. Barcelona: Crítica.

PAZ ARES, C. (2003): "La responsabilidad de los administradores como instrumento de gobierno corporativo", en InDret, núm. 4. https://www.raco.cat/index.php/InDret/article/view/82614/107589.

PONCE SOLÉ, J. (2016): "El derecho a una buena administración y el Derecho administrativo iberoamericano del siglo XXI. Buen gobierno y derecho a una buena administración contra arbitrariedad y corrupción", en REGUERA, E. M. (ed.): El control de la actividad estatal, págs. 219-247. Universidad de Buenos Aires.

RAMIÓ, C. (2011): "Estrategias para la modernización del acceso a la función pública”, en Nuevas Políticas Públicas: Anuario multidisciplinar para la modernización de las Administraciones Públicas, núm. 7, págs. 129-144.

RAMIÓ, C. (2016): La renovación de la función pública. Estrategias para frenar la corrupción política en España. Madrid: Catarata.

RICHARDSON, H. S. (1999): "Institutionally Divided Moral Responsibility", en PAUL, E. F.; MILLER, F. D.; PAUL, J. (eds.): Responsibility, págs. 218-249. Cambridge University Press. https://doi.org/10.1017/ CBO9780511524103.009.

RIVERO ORTEGA, R. (2020): Responsabilidad personal de autoridades y empleados públicos. El antídoto de la arbitrariedad. Colección Ediciones El Cronista. Madrid: Iustel.

ROLDÁN XOPA, J. (2013): La rendición de cuentas y responsabilidad por actividad discrecional y omisión. México: CIDE. http://rendiciondecuentas.org.mx/wp-content/uploads/2013/11/07_RCC_JoseRoldan_190813.pdf.

SÁINZ MORENO, F. (1976): Conceptos jurídicos, interpretación y discrecionalidad administrativa. Madrid: Civitas.

SUMMERS, R. (1978): "Two Types of Substantive Reasons: the Core of a Theory of Common-Law Justification", en Cornell Law Review, vol. 63, núm. 5, págs. 707-778.

VÁZQUEZ, R. (2007): "Corrupción política y responsabilidad de los servidores públicos", en Doxa. Cuadernos de Filosofía del Derecho, núm. 30, págs. 205-216. https://doi.org/10.14198/DOXA2007.30.30.

VILLORIA, M. (2012): "Integridad", en Eunomía. Revista en Cultura de la Legalidad, núm. 1, págs. 107-113. https://erevistas.uc3m.es/index.php/EUNOM/article/view/2160/1093.

WEBER, M.; RUBIO LLORENTE, F. (trad.) (1981): El político y el científico. Madrid: Alianza Editorial. 7. ${ }^{\text {a }}$ ed. 